Editorial

\title{
Scarcity and Environmental Impact of Mineral Resources-An Old and Never-Ending Discussion
}

\author{
Mario Schmidti \\ Institute for Industrial Ecology, Pforzheim University, Tiefenbronner Str. 65, 75175 Pforzheim, Germany; \\ mario.schmidt@hs-pforzheim.de; Tel.: +49-723-128-6406
}

Received: 6 December 2018; Accepted: 19 December 2018; Published: 21 December 2018

\begin{abstract}
A historical overview shows that mankind has feared the scarcity of mineral resources, especially metals, for many centuries. In the first half of the 20th century, this discussion was marked by the great military demand for raw materials, followed by the growing world population, increasing consumption and environmental awareness. From then on, there was less talk of regional shortages, but more discussion of a global scarcity or even a drying up of raw material sources worldwide. Although these forecasts are still controversially discussed today, the assessment of resource depletion has become an integral element of Life Cycle Assessments (LCA) or Life Cycle Impact Assessments (LCIA) of product systems. A number of methodological approaches are available for this purpose, which are presented and applied in a series of articles as part of a special issue of "Resources". The fundamental question is also addressed, namely to what extent the assessment of resource depletion in the context of an environmental study such as LCA is appropriate.
\end{abstract}

Keywords: resource depletion; critical materials; history; life cycle assessment

\section{Introduction}

In October 2015, a workshop entitled "Mineral Resources in LCIA: Mapping the path forward" took place in London. Richard Herrington of the Natural History Museum London and Johannes Drielsma of Euromines organized a meeting in which geologists, mining experts, and environmental scientists came together to present their different views on how to handle mineral resources, but also to look for commonalities. A fruitful discussion arose and the idea came up to record some of the thoughts. These records lead to a special issue of the magazine "Resources", which was published online in 2016. At the same time, there were other activities on this topic, e.g., various studies of the German Federal Environmental Agency, which contributed to the magazine with an article and delivered another paper in 2017 [1]. Meanwhile, there are other important publications on the subject, e.g., a statement and a joint report by the German Academy of Sciences of Technology, the National Academy of Sciences Leopoldina, and the Union of German Academies of Sciences [2,3], as well as a previously unreleased report by an international working group of experts of Life Cycle Assessment (LCA) [4]. There is still no uniform opinion on this important issue, but there is an intensive debate involving many different disciplines. The topic of scarcity and supply reliability has been discussed for a very long time, again and again, which proves a look into history. Therefore, in this introduction, not only are the contributions of the special edition briefly presented, but a reference to the long history of the discussion is made, and some rare sources are quoted by way of example.

\section{Resource Scarcity in the Past}

Two things make it so difficult to supply the industrial society with mineral raw materials and with metals in particular - they are limited on earth, and their extraction is associated with great effort 
and environmental pollution, both of which have concerned mankind for many centuries. In the 16 th century, however, even a renewable resource threatened to become scarce-forests were cleared all over Europe because wood was the predominant raw material for mining and for the fires of melting furnaces. The Italian metallurgist Vannoccio Biringuccio (1480-1539) already warned in his "De la Pirotechnia" in 1540:

"I rather believe that someday people can no longer use the fire for the melting furnaces due to the lack of ores, because they process so much of it" (Chapter 10 in [5]).

It was not sure if the metal ores were a non-renewable resource at all. From the Italian island of Elba, which was an important iron ore deposit at the time, the following was said:

"With the quantities of ore that have been gained in so many centuries and still are gained, the mountains and islands would have to be completely leveled. Nevertheless, today more and better ore is produced than ever. Therefore, many believe that the ore, where it is mined, regenerates in the ground in a certain amount of time. If it is true, it would be something great, and it showed the great wisdom of nature and the great power of heaven" (Chapter 6 in [5]).

Unfortunately, it is not true, at least not in the time scale that is relevant to mankind. Thus, the search for the rare resource deposits has always been a great challenge to mankind. In this search, a variety of means has been employed, such as divining rods, which were already graphically demonstrated by the great German mining expert Georgius Agricola (1494-1555) (Figure 1). It was also Agricola who cited the critics of his time and described the environmental impact of mining and smelting:

"By mining for ore, the fields are devastated. By clearing the forests and groves, the birds and other animal species are eradicated. The ores are washed; but by this washing, because it poisoned the streams and rivers, the fish are either expelled from them or killed" (1st book in [6]).

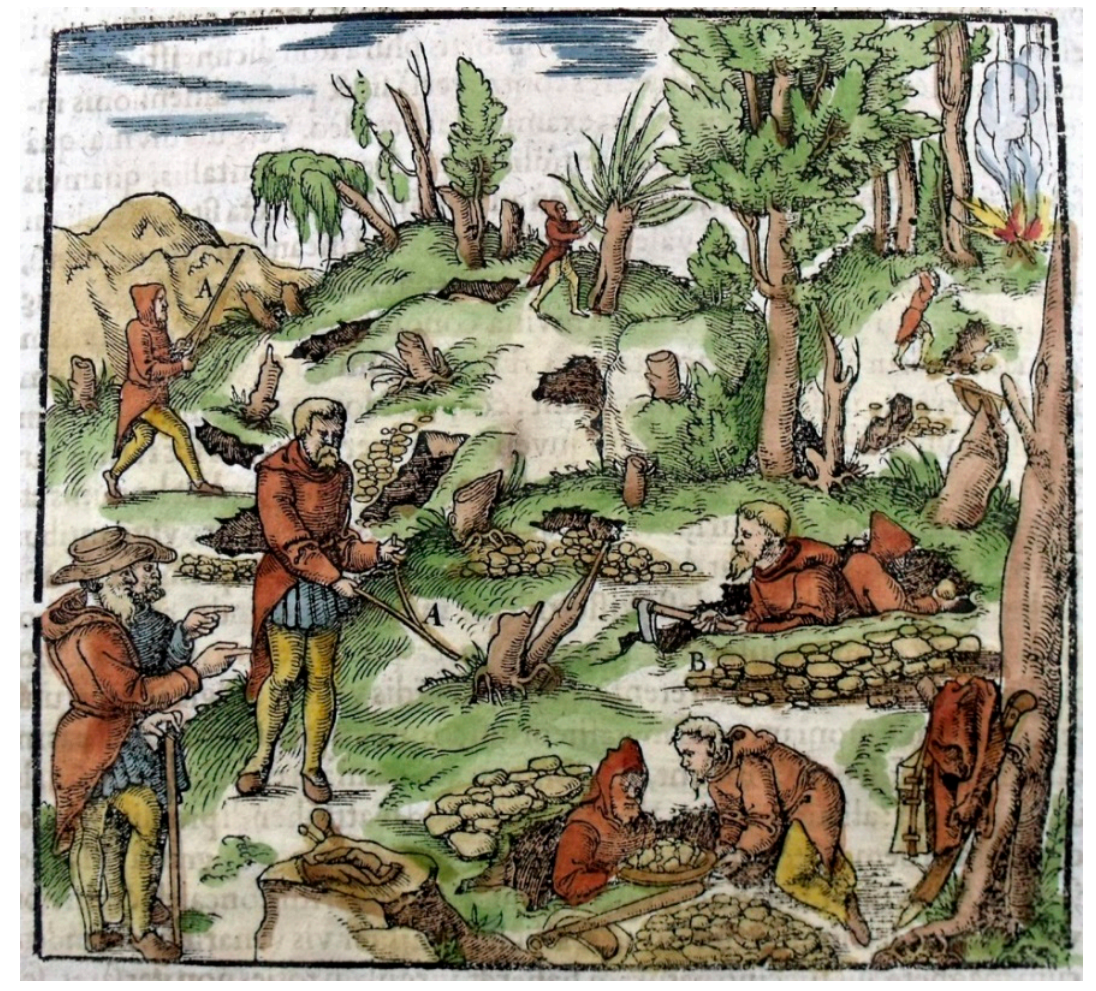

Figure 1. Searching the lodes with the divining rod in the 16th century [6].

But Agricola, of course, defended mining, for it was already an important basis of civilization at that time. Previously, the use conflicts and the interventions in the landscape by mining were addressed by Paulus Niavis (1455-1517) [7]. 
The real scarcity of metal ores came during industrialization, when demand for metals sharply increased. Three hundred years ago, local shortages in England led to a nationwide ore trade [8]. The famous British economist Stanley Jevons posed the "coal question" in 1865. He saw limited coal supplies in face of rampant economic growth and advocated more moderate growth [9].

\section{Critical and Strategic Metals}

With modern times, the demand for metals increased immeasurably. In 1820, 1.65 million tons of pig iron was produced worldwide compared to 41 million tons in 1900, 250 million tons in 1960, and 1.2 billion tons today [10,11]. At the beginning of the twentieth century, a broad conservation movement was emerging in the U.S., focusing primarily on the limitations and protection of natural resources, including minerals, forests, soil, and fisheries, especially in the face of the rapidly growing US economy $[12,13]$.

With the First World War, there was a growing concern in the United States that the supply of strategic raw materials could become difficult because international trade came partially to a halt [14]. An initial list of materials (Table 1), the supply of which could be of concern to the U.S., was published by C.K. Leith in 1917 for the War Industries Board [15]. The boundaries between military and industrial significance were still blurring. A second list of 42 materials was produced after World War I in 1921 by a committee led by General Harbord with a primarily military orientation [16]. The distinction between strategic and critical materials was first made in 1932. In 1939, the War Department compiled a list that included the term "essential material" [17]. The definitions were:

- Strategic Materials are those materials essential to the national defense for the supply of which in war dependence must be placed in whole, or in large part, on sources outside the continental limits of the United States, and for which strict conservation and distribution control measures will be necessary.

- Critical Materials are those materials essential in the national defense, the procurement problems of which in war, while difficult, are less serious than those of strategic materials, because they can be either domestically produced or obtained in more adequate quantities or have a lesser degree of essentiality, and for which some degree of conservation and distribution control will be necessary.

- Essential Materials are those materials essential to the national defense for which no procurement problems in war are anticipated, but whose status is such as to require constant surveillance because future developments may necessitate reclassification as strategic or critical.

Table 1. The first lists of strategic and critical materials in the U.S.

\section{Leith List 1917}

Deficient in a major degree: Tin, Nickel, Platinum and metals of the platinum group, Antimony, Vanadium, Zirconium, Mica, Monazite, Graphite, Asbestos, Ball clay and kaolin, Chalk, Cobalt, Naxos emery, Grinding pebbles.

Deficient in a lesser degree: Nitrates (except potassium nitrates), Potash, Manganese, Chromite, Magnesite.

\section{Harbord List 1921}

Agar, Antimony, Arsenic, Asphalt, Balsa, Camphor, Chromium, Coconut Shells, Coffee, Cork, Graphite, Hemp, Hides, Iodine, Jute, Kapok, Linseed Oil, Manila Fiber, Mercury, Mica, Nickel, Nitrogen, Nux Vomica, Opium, Palm Oil, Phosphorus, Platinum, Potassium Nitrate, Quinine, Rubber, Silk, Manganese (Ferro-grade), Shellac, Sodium Nitrate, Sugar, Sulphur, Thymol, Tin, Tungsten, Uranium, Vanadium, Wool.

\section{War Department List 1939}

Strategic: Aluminum, Antimony, Chromium, Manganese, Mercury, Mica, Nickel, Tin, Tungsten. Critical: Asbestos, Cadmium, Cryolite, Fluorspar, Graphite, Iodine, Platinum, Titanium, Vanadium. Essential: Abrasives, Arsenic, Chlorine, Copper, Helium, Iron and Steel, Lead, Magnesium, Molybdenum, Ammonia and Nitric Acid, Petroleum, Phosphates, Potash, Refractories, Sulfur and Pyrite, Uranium, Zinc, Zirconium. 
In the 1930s, several of the U.S.-governmental institutions' other authors recommended the creation of strategic stocks of so-called scarce minerals [17-19]. In 1939, the first federal law authorizing stockpiling of strategic materials was enacted in the U.S. This stockpiling exists still today in the U.S. and is operated by the National Defense Stockpile (NDS). The total inventory of the NDS represented a market value of $\$ 1.15$ billion in 2016 [20].

Thus, the concept of critical materials was introduced, as well as the academic attention to the scarcity of industrial or defense-related raw materials. It was always more about the topic of which raw materials were available for the U.S. economy (or military forces) and less about how many raw materials were available worldwide.

The scarcity and availability of resources was then repeatedly addressed, e.g., with the "Road of Depletion", which was presented in a hearing of the U.S. Senate 1949 by James Boyd, the director of the U.S. Department of Mining (Figure 2) [21]. At that time, it was already very clear that only $7 \%$ of the world's population, namely in the U.S., use $50 \%$ of the world's minerals and $70 \%$ of the world's oil. The U.S. president installed a Materials Policy Commission, which in 1952 submitted a major report titled "Resources for Freedom" [22]. The Cold War was also a contest for economic power and access to natural resources. In 1963, a large systematic empirical study by Barnett and Morse of historic trends for various natural resources between 1870 and 1958 eventually supported the hypothesis of a decreasing (rather than an increasing) scarcity [23]. They represented a critical but nevertheless optimistic picture of the resource question. They believed in technical progress and in raising efficiency.

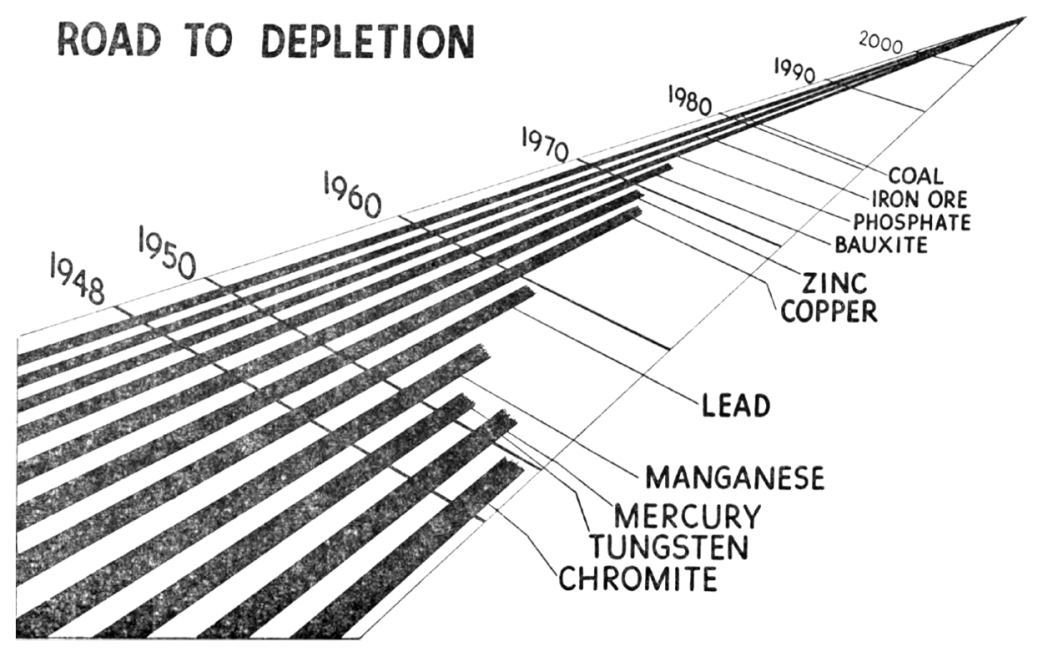

Figure 2. James Boyd: "The chart indicates the number of years of normal requirements our present known reserves of critical materials will supply" [21].

This optimistic picture changed fundamentally in the 60s through wake-up calls such as Ehrlich's book, "The Population Bomb" [24], but especially with the Club of Rome study by Meadows, "The Limits to Growth" in 1972 [25]. Limited natural resources would be confronted with an almost rampant growth of world population and global economic output. Now, it was increasingly about the global development, and the careless handling of the resources was criticized. For example, a study by the U.S. National Academy of Sciences (NAS) asked for increased recycling in 1969: "The automobile is a prime target for improvement. The copper content of the average car should be reduced from about 1.4 percent to 0.4 percent or less of the total carcass and problems of metal recovery simplified" [26]. Recycling became a guiding theme of environmental policy in the following decades.

In 1975, the NAS prepared another report on "Mineral Resources and the Environment" [27]. Not only was the scarcity of raw materials-both energetic and non-energetic-addressed, but also the environmental impact in particular, which was demonstrated by the example of coal extraction and use. A "conservation ethic" was demanded, which could just as well have been formulated today: 
"Because of limits to natural resources as well as to means for alleviating these limits it is recommended that the Federal Government proclaim and deliberately pursue a national policy of conservation of material, energy and environmental resources, informing the public and the private sectors fully about needs and techniques for reducing energy consumption, the development of substitute materials, increasing the durability and maintainability of products, and reclamation and recycling" (page 37 in [27]).

The NAS pointed out that the stockpiling of materials in the past was mainly for military reasons. It was stated that "similar considerations can often be applied to the protection of the U.S. economy and the essential needs of the civilian sector" (page 34 in [27]). This had changed little until today.

The two updates to the Barnett \& Morse study, "Scarcity and Growth Reconsidered" [28] and the study of Menzie, Singer, and DeYoung, Jr. in "Scarcity and Growth Revisited" [29] essentially confirmed the old results that there is no geological scarcity. Menzie et al. noted that the physical availability of resources in itself does not constitute a growth limit. However, the effort required to obtain them is growing, although many resources remain abound. It is obvious that supplies of mineral resources were first used most intensively in the areas closest to their use. As demand increased, exploration and eventually extraction across oceans in inhospitable climates, always deeper into land and water, occurred. Thus, costs, energy input, and the destruction of the environment associated with the extraction increased. Menzie et al. directed the attention to the fact that it is not the limited quantities of raw materials but the accompanying circumstances of their extraction that are the real problem.

Nevertheless, the image of the ebbing raw material sources became apparent to the public. The study by Meadows, which has made popular the very descriptive concept of resource lifetime [25], has contributed significantly to this. The Meadows team introduced the "static reserve life index", which states how many years the known reserves of a given resource will last when the current annual consumption is assumed. With the exponential index, a continuously increasing consumption is expected, which again significantly reduces the time the reserves are available. It hit a nerve with the public and was quoted from time to time, but it was also discussed controversially. Yet, Gerling and Wellmer found out that raw material lifetimes did not decrease over the decades, but mostly stayed the same or even increased [30]. The indicator describes the economic effects of exploration in the mining industry rather than a geological scarcity.

The discussion of the past decades was also marked by reports from the U.S. For its first report in 1988, the U.S. National Critical Materials Council, founded by president Ronald Reagan, selected seven key commodities from three basic categories into which strategic and critical materials were broadly divided [31]. These included: (1) critical alloys—cobalt, chromium, and ferrosilicon; (2) potential high growth security materials-germanium and titanium; and (3) high-volume materials-aluminum and copper. Again, the strategic importance of supply and demand, the current status of the so-called National Defense Stockpile, and the global situation of the import dependence and vulnerability of the U.S. economy were discussed.

Recently, various incidents have come together; countries in Asia, South America, and Africa are claiming an ever-increasing share of resources to build their economies and to supply their populations. The global commodity prices rose rapidly in the first decade of the 21st century, causing a public "resource shock". At the same time, technical innovation has become increasingly dependent on the quantity and variety of raw materials. Many high-tech products have become indispensable in today's life, but they cannot be produced without certain raw materials. A possible scarcity of raw materials endangers not only the military-strategic position of nations, but the way-of-life of the previously wealthy countries and their primacy in the technological development of new products. In addition, there is a global ecological conscience that questions the social and ecological consequences of the use of resources. 
These thoughts have been reflected in the report "Minerals, Critical Minerals, and the U.S. Economy" of the Committee on Critical Mineral Impacts of the U.S. Economy of the National Research Council, which was published in 2008 [32]. The report developed the current method of the semi-qualitative description of the criticality of raw materials with a multi-dimensional evaluation matrix. The impact of supply restriction is plotted against the supply risk as a two-dimensional graph and determined individually for the various raw materials.

An important boost provided the work of the International Resource Panel of United Nations Environmental Programme (UNEP), which published several reports on the subject of metal resources between 2009 and 2014 [33] and in particular called for increased efforts to recycle. In 2016, the U.S. National Science and Technology Council (NSTC) published a report that provided a systematic methodology for screening potentially critical minerals [34,35]. Another detailed report was issued by the U.S. Geological Survey in 2017 [36]. In Europe, a corresponding list was issued by the European Commission. The first list of "Critical Raw Materials" was prepared in 2010; updates were made in 2014 and 2017 [37-39]. Most recently, the 2017 assessment included a total of 78 individual materials.

The disadvantage of these presentations is that they are only short to medium term aligned, and thus the long-term supply situation is not taken into account for the obvious and above mentioned reasons. Furthermore, it is purely economically oriented and ecological aspects are largely missing.

It was Thomas Graedel and his team who developed a three-dimensional criticality system in which the environmental impact has its own dimension [40]. A similar approach was recently published by the German Federal Environment Agency [41]. It is currently being applied to a variety of chemical elements. Results can be expected for 2019. However, it is already evident that the environmental impact associated with the extraction and processing of raw materials can hardly be described with cardinal scales, as is known from LCA. For this purpose, too many site-specific qualitative aspects, at the mining sites for example, have to be considered. This makes the implementation in the framework of LCA difficult.

What can we learn from the past? The scarcity of resources is not new. Concern for the drying up of raw materials is probably as old as mankind itself. The striking of raw materials has always been associated with labor and effort. The estimation of scarcity in each epoch was always done against the background of the respective knowledge available, but the interests connected with the raw materials were also very decisive. It becomes very clear that, especially in the past 100 years, the military interests played an important role and still do today. Many high-tech products that require special raw materials are indispensable to the military. They have a strategic meaning. In the public and scientific discussion, however, it is argued as increasingly "civil" and linked to the material and energy-intensive "way-of-life". An important role is played by the LCA of products and services, which quantifies the impact on the environment. The use of resources is an integral part of the analysis and evaluation.

\section{Abiotic Resources in Life Cycle Assessment (LCA)}

When an LCA is carried out for products or services, it is now standard practice to include and quantify the use of natural resources. The Life Cycle Inventory still does this on a physical and quantitative basis, i.e., the amount of required raw materials and the withdrawals from nature is quantified. For example, the use of water as a natural resource is included. It has also become customary to consider the required land use. However, the pure quantities $\left(\mathrm{m}^{3}\right.$ of water or $\mathrm{km}^{2}$ of area) are not sufficient to describe the environmental quality of the resource input, yet this is needed in the following step of an LCA, the Life Cycle Impact Assessment (LCIA), where the ecological relevance of the energy and material flows is quantified. To get from the amount of a substance to the effect of the substance, so-called characterization factors are used in the LCA. They are a simplification for the LCA calculation, and all the knowledge about the ecological effect of a substance is hidden behind them. Their investigation is therefore always in the focus of the interests of many authors from the LCA community. 
This task also arises for the mineral resources taken from the lithosphere. The input of metals that originate from nature and enter the technosphere is one thing, but what is the ecological relevance of the volume flows of iron, copper, tantalum, indium, gold, etc.? The energy demands, the wastewater, and the emissions associated with the extraction and processing of raw materials are already included in an LCA. These environmental aspects of mining and metalworking are automatically considered; thus double counting must be avoided. Rather, it is about the question of how the extraction of raw materials from the lithosphere "in itself" can be evaluated.

In the field of Life Cycle Assessments, the safeguard objects and the so called "Areas of Protection" (AoP) have been discussed for many years [42-44]. It is not only interesting to know what impact a human action has on the climate, the acid rain, or the eutrophication, but what that impact means for the safeguard objects, especially for human health and for the integrity of nature, which is often circumscribed with the preservation of biodiversity. In addition, there is a third safeguard object, namely the preservation of natural resources [45-47]. Strictly speaking, this is not an ecological aspect, but it is more subject to the idea of sustainability. The consumption of a limited natural resource eventually leads to its depletion. What is not kept in the cycle of nature disappears at some point and is no longer available for future generations, which would not meet the idea of sustainability.

However, does the mining of minerals and possibly the depletion of metals really belong to an ecological analysis like the Life Cycle Assessment? Are these not rather socio-economic aspects that cannot be adequately illustrated with the methodological instruments of the LCA? This issue has been the subject of much controversy for many years. In an attempt to hierarchize the safeguard objects in the life cycle assessment, Hofstetter and Scheringer (1997) based the LCA on human welfare and divided it into the social welfare of today's generations and the material welfare of future generations [48]. They identified additional safeguard objects related to resource supplies, human health, biodiversity, and ecological health (Figure 3).

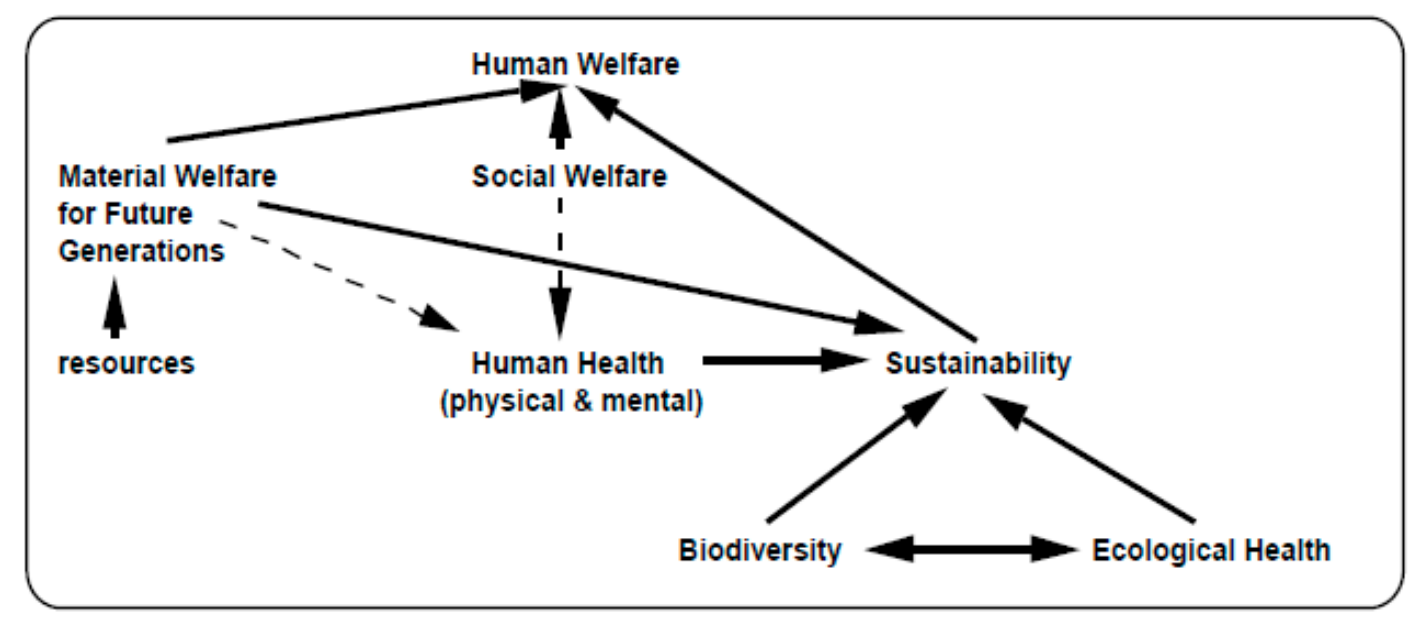

Figure 3. Proposal for the hierarchy of safeguard objects in the Life Cycle Assessment according to [48].

The safeguard object "resources" could be interpreted in such a way that a reduction of the resource supply or the lower quality of future mineral deposits restricts the freedom of action of coming generations and imposes higher efforts on them. Especially with regard to sustainability and intergenerational justice, the protection of mineral resources would then be worth considering. It is controversial if this should be considered in an environmental analysis such as the LCA. Social issues, for example, are excluded from the LCA and treated with their own instrument, the "Social LCA". If there were a suitable instrument to assess economic sustainability, such as influencing the welfare of future generations through current activities, the resources would have to be considered in this assessment. However, this instrument does not exist. This can be seen as a justification for today's explicit inclusion of resources as safeguard objects by the LCA methodology as a stopgap for the inability of economics, so to speak. 
The basic aspect of whether or not resources should be considered as safeguard objects is hardly questioned by the LCA community today [4]. One may criticize this because it is based on the claim to model nearly everything with the LCA that concerns the metabolism of the technosphere and its exchange with the biosphere. There are far more relevant questions to be asked, such as whether the simple linear LCA approach can adequately address the dynamic effects of technological innovation or market developments. Another difficulty is finding suitable indicators for a quantitative assessment within the LCA. Finally, the amount of remaining inventory or usage restriction for future generations would have to be quantified in some way. However, this is largely unknown today, just as in the past (see Chapter 1) it was unknown what resources would be available to us in the 20th or 21st century.

In summary, three questions play a role at the interface between the resource topic and the Life Cycle Assessment:

1. How scarce are the mineral resources, and in particular the metals, and do we really know the amount of mineral resources left in the earth?

2. Do we have to understand the mineral resources in nature as protective goods that, in addition to health and biodiversity, have to be protected and preserved for reasons of sustainability?

3. Which environmental impacts occur through the mining of resources and the extraction of metals, and are they adequately reflected in the method of the Life Cycle Assessment?

\section{Contributions to the Main Topic}

The discussion at the 2015 workshop in London triggered this discussion and is well documented by some articles from participants. There are also additional contributions that round off the topic altogether. Drielsma et al. [49] gave an overview of the discussion in London that included the points of contact of the various scientific disciplines, the different perspectives on the subject, and the difficulties of definition that sometimes complicate scientific exchange.

Meinert et al. [50] advanced a point of view that can be found among many geologists. They described how mineral resources are explored and discovered, which leads to predictions about known deposits and which definitions are used for them. They used the example of copper because very different opinions about the scarcity of this metal exist and it has been mined in large quantities for a long time. In this example, they tried to show that the lifetime concept-or the peak concept-is based on wrong assumptions and therefore leads to misinterpretations. According to their statements, by 2050, only half of the previously known and already economically degradable stocks will be needed, and the undiscovered copper deposits are not yet included. By estimating these deposits, their optimistic prognosis was that primary copper will still be available for many generations. The authors argued that less concern should be paid to the depletion of primary resources but rather what happens to resources after their extraction and how they are used with regard to dissipation. On this point, there is certainly a broad consensus with other experts who have a more "resource-pessimistic" attitude. But the most important point of their contribution may be to suggest that society is investing too little in education, research, and development to ensure the supply of raw materials for future generations. The mining sector in particular needs stronger state support. When more environmentally compatible and efficient mining methods are used, there will certainly be broad consensus on this point.

The article by Oers and Guinée [51] was particularly special because it was a kind of update and reflection on an approach that is widely used in the LCA community. In 1995, Guinée and Heijungs proposed characterization factors for abiotic depletion potential (ADP), which were widely used in the application of the LCA [52]. Again, the use of terms played an important role. Do we talk about depletion, scarcity, or criticality? Should the ultimate reserves, the reserve base, or the crustal content be used as a basis for comparisons between different metals? The authors emphasized that there is probably more than a dilution problem, namely when resources are released into the environment through emissions or wastes and are irretrievably lost. However, they also pointed out that it is difficult to define the correct method because the parameters to be chosen depend on the question and cannot be empirically verified in practice. 
Calvo et al. [53] drew attention to an interesting aspect-what does the mineral capital of various countries look like? Through the mining and export of minerals, this capital is changing. What exergy would be needed to rebuild this lost mineral capital? An average concentration of minerals in the earth's crust is assumed. The authors created a kind of a mineral balance based on exergy replication costs. Evaluating the exergy with prices (for electricity or coal) leads to an economic statement. Using the examples of Colombia and Spain, the authors showed that mining and exporting minerals produces a lower gross domestic product than one would have to pay for exergy replacement costs to rebuild the mineral capital. The figures could also be used to produce net balances between countries. This issue has a high economic and developmental importance due to the unequal distribution of raw materials among countries and the question of fair pay for raw materials supplies.

Vieira et al. [54] calculated the surplus costs arising from current resource extraction on future situations and used these as a basis to calculate characterization factors for 12 metals and the platinum group metals. In the tradition of many environmental scientists, they assumed the absolute finiteness of mineral resources. They further assumed that with increasing mine production, the ore grades decrease and a grade-tonnage relationship can be set up. They derived a function for the operating costs per metal extracted, which depends on the previous amount of cumulative metal extracted and the total amount of a metal that can be mined on earth or has already been mined. The interesting thing about the approach is that the choice of this last value has only a limited effect on the result. The authors pointed out that they had not yet considered many cost drivers and therefore need to gather more data.

At the focus of the article by Henßler et al. [55] was the application of a method called ESSENZ, which was developed at the Technical University of Berlin to evaluate many aspects of the use of resources. These aspects included physical availability as well as socioeconomic availability and environmental impacts. A total of 18 categories were taken into account, some category examples being abiotic resource depletion, the political stability of producing countries, and the impact of summer smog. The authors presented a case study in which ESSENZ was applied to the comparison of a conventional car and an e-car from Mercedes. The method provides greatly differentiated results for the different categories. In particular, it allows the comparison of tradeoffs that may occur when environmental impacts are reduced, but the use of resources increases at the same time.

In their article, Martin-Gamboa and Iribarren [56] examined and compared the performance of wind turbines, taking into account the use of raw materials. The starting point was, of course, data from the LCA, but they used a method that goes far beyond the pure LCA approach. They used emergy as an indicator, which is the solar energy that is or was ultimately required to manufacture a product by extracting resources from the geo-biosphere. This approach is similar to corresponding exergy approaches in resource use assessment. This is connected, as they wrote, with a departure from the purely anthropocentric perspective. Gamboa and Iribarren went even further and used the data envelopment analysis (DEA) for time-dependent efficiency measurements of various wind farms.

Alvarenga et al. [57] analyzed, in a very extensive study, the different methods with which abiotic raw materials are evaluated in LCA. They also dealt with the question of the area of protection and which impact assessments are useful. In total, they considered 19 different Life Cycle Impact Assessment methods, some of which treat the topic of resources very differently. They tested the methods using a case study comparing fossil and bioethanol-based ethylene production.

Finnveden et al. [58] made a very important contribution by considering the crucial question of what is actually depleted or consumed. Their answer was that it is neither matter nor energy, but usable energy, i.e., exergy. The big advantage to this is that the evaluation of matter and energy can be integrated into a unified concept. However, this thermodynamic approach requires extensive calculations. The question that remains open is what practical relevance the calculation of the more theoretical exergy values has. This must be further discussed in the future at case studies.

Müller et al. [1], in a very committed, detailed, and far-reaching article, dealt with the fundamental questions of which goals one wants to achieve with dematerialization and which indicators are 
meaningful for this purpose. They dealt with normative aspects in the discussion, cited examples from German and European resource efficiency policies, and came to the conclusion that mass-based indicators are rather unsuitable to describe the desired AoP of environmental protection. At the same time, however, they also advocated an environmental policy that does not stop at national borders but takes a life cycle perspective.

\section{Outlook}

The presented articles show that the question of the depletion of resources and their assessment in the LCA is by no means conclusively answered. There are many opinions and different approaches. Above all, however, it is an interdisciplinary question that has a lot to do with methods and experiences from environmental sciences, but most significantly with geology, resource economics, and mining. The positions on the depletion question depend very much on different specialists' knowledge, but also on the normative positions of the various disciplines. It is therefore quite understandable that representatives from the environmental sciences assume that resources will soon be exhausted. Representatives from the mining sector, on the other hand, must start from the inexhaustibility of resources. This is the basis of their business model.

Nevertheless, recommendations for politics and for the economy are necessary, such as which criteria are used to assess recycling strategies or a circular economy. If the depletion of resources is an independent and urgent issue, a circular economy would have absolute priority. In this case, this might have to be weighed against other objectives, e.g., climate protection. Conflicting goals could arise here since the achievement of the $1.5^{\circ}$ goal requires an enormous expansion and the restructuring of energy supply structures worldwide. This would require a considerable use of resources that could only be covered by additional primary resources. If, however, the problem of resource depletion is postponed or perceived only as an exergy or entropy problem, then the energy balance and the environmental impacts of resource supply come to the fore, both from mining and from recycling. These can be dealt with very well in today's LCA framework.

This is why the discussion on this topic is more important than ever. However, this time it must lead to a result and must not get stuck in different schools of thought as it did 40 years ago. Above all, the exchanges between the various scientific disciplines and applications in economy are important. Therefore, the meeting in London, which resulted in most of the articles presented in this paper, was an important event that urgently needs to be repeated on an interdisciplinary and open platform.

Funding: This research received no external funding.

Conflicts of Interest: The author declares no conflict of interest.

\section{References}

1. Müller, F.; Kosmol, J.; Keßler, H.; Angrick, M.; Rechenberger, B. Dematerialization-A disputable strategy for resource conservation put under scrutiny. Resources 2017, 6, 68. [CrossRef]

2. German National Academy of Sciences Leopoldina; National Academy of Science and Engineering (acatech); Union of the German Academies of Sciences and Humanities. Raw Materials for the Energy Transition; Acatech: Munich, Germany, 2018.

3. Wellmer, F.-W.; Buchholz, P.; Gutzmer, J.; Hagelüken, C.; Herzig, P.; Littke, R.; Thauer, R.K. Raw Materials for Future Energy Supply; Springer: Berlin, Germany, 2018.

4. Berger, M.; Sonderegger, T. Global Guidance for Life Cycle Impact Assessment of Mineral Resource Use. White Paper of the Task Force Resources of Life Cycle Initiative; Berger, M., Sonderegger, T., Eds.; Life Cycle Initiative of UN Environment: Paris, France, 2018; unpublished.

5. Johannsen, O. Biringuccios Pirotechnia; Vieweg: Braunschweig, Germany, 1925. (In German)

6. Agricola, G. De Re Metallica Libri XII, Basel, 1556, 2nd German ed.; Ludwig Königs: Basel, Switzerland, 1621. (In German)

7. Niavis, P. Iudicium Iovis. In Paulus Niavis Iudicium Iovis oder Das Gericht der Götter über den Bergbau Freiberger Forschungshefte D3; Krenkel, P., Ed.; Akademie-Verlag: Berlin, Germany, 1953. (In German) 
8. Selmeier, F. Eisen, Kohle und Dampf. Die Schrittmacher der Industriellen Revolution; Deutsches Museum: München, Germany, 1984; p. 87. (In German)

9. Jevons, W.S. The Coal Question, 3rd ed.; Sentry Press: New York, NY, USA, 1965.

10. Riegraf, H. Geographie der Rohstoffwirtschaft der Erde; Deutscher Verlag der Wissenschaften: Berlin, Germany, 1961; p. 282. (In German)

11. World Steel Association. Steel Statistical Yearbook 2018; World Steel Association: Brussels, Belgium, 2018.

12. Pinchot, G. The Fight for Conservation, Doubleday; Page \& Company: New York, NY, USA, 1911.

13. Blanchard, N.C. (Ed.) Proceedings of a Conference of Governors in the White House Washington, DC 13-15 May 1908; Government Printing Office GPO: Washington, DC, USA, 1909.

14. Leith, C.K. The Economic Aspects of Geology; Henry Holt and Company: New York, NY, USA, 1921.

15. Leith, C.K. International Control of Minerals. In Mineral Resources of the United States; McCaskey, H.D., Ed.; Department of the Interior: Washington, DC, USA, 1917; pp. 7-17.

16. Spicer, L.G. Stock Piling of Strategic Materials. Master's Thesis, Boston University, Boston, MA, USA, 1950.

17. Roush, G.A. Strategic Mineral Supplies; McGraw-Hill: New York, NY, USA, 1939.

18. Emeny, B. The Strategy of Raw Materials; MacMillan: New York, NY, USA, 1936.

19. Eckes, A.E. The United States and the Global Struggle for Minerals; University of Texas Press: Austin, TX, USA, 1979.

20. U.S. Department of Defense, DLA Strategic Materials. Strategic and Critical Materials Operations Report to Congress; Fort Belvoir: Fairfax, VA, USA, 2017.

21. U.S. Senate. Mineral Resources Development. Hearings before the Committee on Interior and Insular Affairs; U.S. Senate: Washington, DC, USA, 1949.

22. House of Representatives. Resources for Freedom; A Report to the President by The President's Materials Policy Commission; House of Representatives: Washington, DC, USA, 1952; Volume I-V.

23. Barnett, H.J.; Morse, C. Scarcity and Growth. In The Economics of Natural Resource Availability; John Hopkins Press: Baltimore, Maryland, 1963.

24. Ehrlich, P.R. The Population Bomb; Sierra Club: San Fransisco, CA, USA, 1968.

25. Meadows, D.H.; Meadows, D.L.; Randers, J.; Behrens, W.W. The Limits to Growth; Universe: New York, NY, USA, 1972.

26. National Academy of Sciences. Resources and Man; Freeman: San Francisco, CA, USA, 1969.

27. National Academy of Sciences. Mineral Resources and the Environment; A Report by the Committee on Mineral Resources and the Environment; National Academy of Sciences: Washington, DC, USA, 1975.

28. Smith, V.K. Scarcity and Growth Reconsidered; John Hopkins Press: Baltimore, Maryland, 1979.

29. Simpson, R.D.; Toman, M.A.; Ayres, R.U. Scarcity and Growth Revisited. In Natural Resources and the Environment in the New Millennium; Resources for the Future: Washington, DC, USA, 2005.

30. Gerling, J.P.; Wellmer, F.-W. Reserven, Ressourcen und Reichweiten. Wie lange gibt es noch Erdöl und Erdgas? Chem. Uns. Zeit. 2005, 39, 236-245. (In German) [CrossRef]

31. Executive Office of the President National Critical Materials Council. A Critical Materials Report-The Continuation of a Presidential Commitment; Executive Office of the President National Critical Materials Council: Washington, DC, USA, 1988.

32. Committee on Critical Mineral Impacts of the U.S. Economy. Minerals, Critical Minerals, and the U.S. Economy; National Research Council: Washington, DC, USA, 2008.

33. International Resource Panel. Work on Global Metal Flows; United Nations Environment Programme: Paris, France, 2013.

34. Committee on Environment, Natural Resources, and Sustainability. Assessment of Critical Minerals: Screening Methodology and Initial Application; National Science and Technology Council: Washington, DC, USA, 2016.

35. Committee on Environment, Natural Resources, and Sustainability. Assessment of Critical Minerals: Updated Application of Screening Methodology; National Science and Technology Council: Washington, DC, USA, 2018.

36. U.S. Geological Survey. Critical Mineral Resources of the United States-Economic and Environmental Geology and Prospects for Future Supply; USGS: Reston, VA, USA, 2017.

37. European Commission. Tackling the Challenges in Commodity Markets and on Raw Materials; COM(2011) 25 final; European Commission: Brussels, Belgium, 2011.

38. European Commission. On the Review of the List of Critical Raw Materials for the EU and the Implementation of the Raw Materials Initiative; COM(2014) 297 final; European Commission: Brussels, Belgium, 2014. 
39. European Commission. On the 2017 List of Critical Raw Materials for the EU; COM(2017) 490 final; European Commission: Brussels, Belgium, 2017.

40. Graedel, T.E.; Barr, R.; Chandler, C.; Chase, T.; Choi, J.; Christoffersen, L.; Friedlander, E.; Henly, C.; Jun, C.; Nassar, N.T.; et al. Methodology of Metal Criticality Determination. Environ. Sci. Technol. 2012, 46, 1063-1070. [CrossRef] [PubMed]

41. Manhart, A.; Vogt, R.; Priester, M.; Dehoust, G.; Auberger, A.; Blepp, M.; Dolega, P.; Kämper, C.; Giegrich, J.; Schmidt, G.; et al. The environmental criticality of primary raw materials-A new methodology to assess global environmental hazard potentials of minerals and metals from mining. Min. Econ. 2018. [CrossRef]

42. Consoli, F. Guidelines for Life Cycle Assessment: A "Code of Practice"; SETAC (Society of Environmental Toxicology and Chemistry): Pensacola, FL, USA, 1993.

43. Beltrani, G. Safeguard Subjects. The Conflict Between Operationalization and Ethical Justification. Int. J. Life Cycle Assess. 1997, 2, 45-51. [CrossRef]

44. Vadenbo, C.; Rørbech, J.; Haupt, M.; Frischknecht, R. Abiotic resources: New impact assessment approaches in view of resource efficiency and resource criticality-55th Discussion Forum on Life Cycle Assessment, Zurich, Switzerland, 11 April 2014. Int. J. Life Cycle Assess. 2014, 19, 1686-1692. [CrossRef]

45. Steen, B.A. Abiotic resource depletion. Different perceptions of the problem with mineral deposits. Int. J. Life Cycle Assess. 2006, 11, 49-54. [CrossRef]

46. Strauss, K.; Brent, A.C.; Hietkamp, S. Characterisation and normalisation factors for life cycle impact assessment mined abiotic resources categories in South Africa. Int. J. Life Cycle Assess. 2006, 11, 162-171. [CrossRef]

47. Mancini, L.; De Camillis, C.; Pennington, D. Security of supply and scarcity of raw materials. In Towards a Methodological Framework for Sustainability Assessment; European Commission Joint Research Centre: Ispra, Italy, 2013.

48. Hofstetter, P.; Scheringer, M. Schutzgüter und ihre Abwägung aus der Sicht verschiedener Disziplinen; 5. Diskussionsforum Ökobilanzen vom 17. Oktober 1997 an der ETH Zürich; ETH Zürich: Zürich, Switzerland, 1997. (In German)

49. Drielsma, J.A.; Allington, R.; Brady, T.; Guinée, J.; Hammarstrom, J.; Hummen, T.; Russell-Vaccari, A.; Schneider, L.; Sonnemann, G.; Weihed, P. Abiotic raw-materials in life cycle impact assessments: An emerging consensus across disciplines. Resources 2016, 5, 12. [CrossRef]

50. Meinert, L.D.; Robinson, G.R., Jr.; Nassar, N.T. Mineral resources: Reserves, peak production and the future. Resources 2016, 5, 14. [CrossRef]

51. Van Oers, L.; Guinée, J. The abiotic depletion potential: Background, updates, and future. Resources 2016, 5, 16. [CrossRef]

52. Guinée, J.; Heijungs, R. A proposal for the definition of resource equivalency factors for use in product Life-Cycle Assessment. Environ. Toxicol. Chem. 1995, 14, 917-925. [CrossRef]

53. Calvo, G.; Valero, A.; Carmona, L.G.; Whiting, K. Physical assessment of the mineral capital of a nation: The case of an importing and an exporting country. Resources 2015, 4, 857-870. [CrossRef]

54. Vieira, M.D.M.; Ponsioen, T.C.; Goedkoop, M.J.; Huijbregts, M.A.J. Surplus cost potential as a life cycle impact indicator for metal extraction. Resources 2016, 5, 2. [CrossRef]

55. Henßler, M.; Bach, V.; Berger, M.; Finkbeiner, M.; Ruhland, K. Resource efficiency assessment—Comparing a plug-in hybrid with a conventional combustion engine. Resources 2016, 5, 5. [CrossRef]

56. Martin-Gamboa, M.; Iribarren, D. Dynamic ecocentric assessment combining emergy and data envelopment analysis: Application to wind farms. Resources 2016, 5, 8. [CrossRef]

57. Alvarenga, R.A.F.; de Olivera Lins, I.; de Almeida Neto, J.A. Evaluation of abiotic resource LCIA methods. Resources 2016, 5, 13. [CrossRef]

58. Finnveden, G.; Arushanyan, Y.; Brandao, M. Exergy as a measure of resource use in life cycle assessment and other sustainability assessment tools. Resources 2016, 5, 23. [CrossRef]

(C) 2018 by the author. Licensee MDPI, Basel, Switzerland. This article is an open access article distributed under the terms and conditions of the Creative Commons Attribution (CC BY) license (http://creativecommons.org/licenses/by/4.0/). 